\title{
A TEORIA DISPOSICIONAL DE SEARLE SOBRE OS FENOMÊNOS INCONSCIENTES E O PROBLEMA DA EFTCÁCIA CAUSAL
}

\author{
Searle's dispositional theory of unconscious phenomena and the problem of the \\ causal efficacy
}

Tárik de Athayde Prata

UFPE

\begin{abstract}
Resumo: Searle defende a perspectiva - historicamente associada a Descartes - segundo a qual a consciência é a essência da mente. Isso gera complicaçós para que ele possa explicar a existência de fenômenos mentais inconscientes - existência que o próprio Searle aceita. Sua estratégia para conciliar (1) a essencialidade da consciência com (2) a existência de fenômenos mentais inconscientes é recorrer a uma teoria disposicional: estados inconscientes existem na forma de disposições (propensões, potenciais) para a causaç̃o de estados conscientes. O presente artigo se concentra em uma dificuldade enfrentada por essa teoria, dificuldade decorrente da eficácia causal que o próprio Searle atribui aos fenômenos mentais inconscientes. Se um fenomeno inconsciente causa uma determinada ação, então ele o faz em virtude de suas propriedades mentais (como o (a) aspecto qualitativo de sensaçoes, ou (b) o conteúdo representativo de desejos), mas se estas propriedades mentais desempenham um papel essencial na causação, então elas existem efetivamente, o que significa que o fenomeno inconsciente possui uma existência mental independente da consciência, o que contradiz a visão cartesiana da consciência como a essência do mental.
\end{abstract}

Palavras-chave: Consciência, Inconsciente, Disposições, Causação mental.

\begin{abstract}
Searle holds the view - historically associated with Descartes - according to which consciousness is the essence of the mind. This creates complications for an explanation of the existence of unconscious mental phenomena - an existence which Searle himself accepts. His strategy to conciliate (1) the essentiality of consciousness with (2) the existence of unconscious mental phenomena is to resort to a dispositional theory: unconscious states exist as dispositions (propensities, potentials) to the causation of conscious states. The present paper focuses on a difficulty faced by this theory, a difficulty due to the causal efficacy which Searle himself attributes to unconscious mental phenomena. If an unconscious phenomenon causes a specific action, it does it due to its mental properties (as (a) the qualitative aspect of sensations, or (b) the representational content of desires), but if these mental properties play an essential role in the causation, then they exist effectively, which means that the unconscious phenomenon has a mental existence regardless of consciousness, thus contradicting the Cartesian view of consciousness as the essence of mental.
\end{abstract}

Keywords: Consciousness, Unconscious, Dispositions, Mental causation.

\section{Introdução}

Durante longo tempo, a noção de fenômenos mentais inconscientes teve um lugar bastante periférico. Em sua influente obra A psicologia do ponto de vista empírico, publicada originalmente em 1874, Franz Brentano declara que milênios se passaram na 
história da Filosofia antes que aparecesse um filósofo que defendesse a noção de inconsciente (cf. Brentano, 1924, p. 144 [103]) $)^{1}$ - noção da qual ele próprio foi um opositor. Mas foi por obra de um aluno de Brentano, o médico e fundador da psicanálise, Sigmund Freud, que foi operada uma inversão nesse estado de coisas (cf. Searle, 1992, p. 151 [218]; Gennaro, 1996, p. 6).

Hoje, a ideia de que fenômenos mentais inconscientes desempenham importante papel em nossa vida psíquica já quase pertence ao próprio senso comum (eventualmente aparecendo, por exemplo, em discursos não acadêmicos veiculados pelos meios de comunicação de massa). Em diversas disciplinas específicas, como na própria psicanálise, mas também na linguística e na ciência cognitiva, a ênfase no inconsciente chega a tal ponto que a consciência chega a ser vista como um aspecto secundário em nossa existência psicológica.

Na tradição da Filosofia Analítica, uma tradição constituída em torno de reflexões sobre a lógica, a linguagem e a teoria da ciência (operadas por pensadores como Gottlob Frege, Bertrand Russell, Rudolf Carnap e Ludwig Wittgenstein), a investigação da consciência não teve muito espaço, até meados da década de 1990. Sob a influência de Wittgenstein e do positivismo lógico, o discurso acerca de processos mentais misteriosos, inacessíveis publicamente, foi visto com desprezo, e a ciência psicológica foi entendida como uma investigação de comportamentos públicos, intersubjetivamente observáveis. Mesmo após a lenta derrocada do behaviorismo lógico na Filosofia Analítica, concepções como a teoria da identidade entre mente e cérebro e o funcionalismo ${ }^{2}$, continuaram buscando um estudo de entidade objetivas, considerando a experiência consciente (puramente subjetiva) como um território inacessível para a investigação científica.

Foram as reflexões de Saull Kripke, no início da década de 1970, que começaram a provocar uma mudança nesse cenário, pois a qualidade fenomenológica da experiência consciente foi vista por ele como um obstáculo para a teoria da identidade entre mente e cérebro (cf. Kripke, 2001, p. 152), e essa reflexão impulsionou o debate sobre a consciência, levado a frente por influentes filósofos como Thomas Nagel (1974), Frank Jackson (1982), Joseph Levine (1983) e David Chalmers (1996).

John R. Searle, professor da Universidade da Califómia em Berkeley, e um dos mais importantes filósofos da atualidade, se insere exatamente nessa tradição de retomada da consciência. Ele considera que as reflexões de Kripke, Nagel e Jackson inviabilizaram o reducionismo reinante ao longo da história da Filosofia analítica (cf. Searle, 1992, p. 117-18 [170-71]) $)^{3}$ e considera essencial reabilitar a investigação sobre a consciência na filosofia da mente. Searle trabalha, assim, em uma perspectiva segundo a qual a consciência é a essência do mental, a mais importante característica do domínio psicológico, aquela característica que possibilita a definição de um fenômeno enquanto ưm fenômeno mental. Nas palavras de Searle:

A razão para enfatizar a consciência numa explicação da mente é que ela é a noção mental central. De uim modo ou de outiro, todas as outiras noçozes mentais como intencionalidade, subjetividade, causação mental, inteligência etc. - só podem ser plenamente compreendidas como mentais por meio de suas relações com a consciência. (Searle, 1992, p. 84 [125-26])

Trata-se de uma perspectiva historicamente associada ao pensamento de René Descartes (cf. Rosenthal, 1986, p. 331; Armstrong, 1997, p. 721; Armstrong, 1999, pp. 14-16; Searle, 2004, p. 13), que em diversas passagens de sua obra defendeu a essencialidade da

\footnotetext{
${ }^{1}$ O primeiro número de página é o da segunda edição alemã, enquanto o número entre colchetes é o da página da tradução britânica.

${ }^{2}$ Sobre a história da Filosofia da Mente, sobre a passagem do behaviorismo lógico para a teoria da identidade e a superação desta pelo funcionalismo, cf. Costa, 2002; Churchland, 2004; Maslin, 2009.

${ }^{3}$ O primeiro número de página é o da edição original, em inglês, enquanto o número entre colchetes é o da página da tradução para o português, quando estiver disponível.
} 
consciência para o psíquico ${ }^{4}$ e, em conformidade a isso, considerou impossível a existência de fenômenos psíquicos inconscientes. ${ }^{5}$ Mas Searle, por seu turno, pretende aceitar a importância do inconsciente para a compreensão de nossa vida mental (cf. Searle, 1992 p. 151 [217]; Searle, 2004, p. 250), de modo que sua adesão a essa concepção cartesiana, provoca imediatamente um questionamento a respeito da noção de fenômenos mentais inconscientes. Se a consciência é a característica definidora do domínio do mental, onde encaixar os fenômenos mentais inconscientes nesse quadro? Nas palavras de Searle:

Como pode existir um estado que é literalmente mental e ao mesmo tempo totalmente inconsciente? Tais estados careceriam de qualitatividade e subjetividade e não seriam parte do campo unificado de consciência. Então em que sentido, se é que há algum, eles seriam estados mentais? (Searle, 2004, p. 23738).

Veremos a seguir que as características da qualitatividade, da subjetividade e da unidade são vistas por ele como aspectos da propriedade essencial da consciência (cf. Searle, 2002, p. 39 [56-57]), de maneira que não parece possível considerar fenômenos inconscientes como fenômenos mentais, já que eles carecem dessas características. Searle procura acomodar o inconsciente em sua teoria através da ideia de que o essencial é a acessibilidade à consciência, a possibilidade (em princípio) de um dado fenômeno se tornar consciente. $\mathrm{O}$ que define um fenômeno como mental é a sua possibilidade de ser consciente, e não a sua consciência efetiva. Porém, ao mesmo tempo em que ele aceita, de certo modo, os fenômenos mentais inconscientes, Searle defende que a ontologia desses fenômenos (o seu modo de existência) é uma ontologia não mental, objetiva, pois (segundo ele) quando há um fenômeno mental inconsciente, tudo o que há são padrões de atividade eletroquímica em arquiteturas neuronais, padrões estes que teriam a capacidade de causar fenômenos conscientes (subjetivos) nas circunstâncias adequadas. Searle defende, portanto, uma concepção disposicional dos fenômenos mentais inconscientes. ${ }^{6}$

Curiosamente, embora Searle pareça considerar essa concepção disposicional do inconsciente como uma contribuição original de sua parte (cf. Searle, 1992, p. 160-61 [23031]), essa concepção já é bastante antiga, pois o próprio Brentano (que era um adversário da tese do inconsciente), já a mencionava, como uma boa explicação do modo de existência desses fenômenos. De acordo com Brentano:

Naturalmente eles [os filósofos] estavam bem familiarizados com o fato de que se pode possuir um tesouro de conhecimentos adquiridos, sem pensar neles; mas de modo totalmente correto [grifo meu] eles concebiam os mesmos como disposições [Dispositionen] para certos atos de pensar, como também concebiam o caráter adquirido como disposição para certos afetos e atos de vontade, mas não [grifo meu] como conhecimento e consciência." (Brentano, 1924, p. 144 [103]).

Quando diz que filósofos do passado entenderam de modo totalmente correto que conhecimentos inconscientes existem na forma de disposições, Brentano está expressando sua adesão ao mesmo tipo de concepção defendido por Searle (além de indicar que essa visão disposicional já era conhecida antes do século XIX). E o próprio Freud, provavelmente o maior responsável pela difusão da ideia de inconsciente, se

\footnotetext{
${ }^{4}$ Descartes definiu o pensamento, aquilo que ele concebia enquanto a propriedade essencial do psíquico, como "tudo quanto está de tal modo em nós que somos imediatamente conscientes." (Descartes, 1979, p. 169 [AT, VII, p. 160, AT, IX, p. 124]). Os números romanos dão as referências nos volumes em latim (volume VII) e em francês (volume IX) da edição completa das obras de Descartes feita por Charles Adam e Paul Tannery (AT).

5 "Nenhum pensamento pode existir em nós do qual nos não estejamos conscientes no exato momento em que ele existe em nós" (cf. AT, VII, p. 246; AT, IX, p. 190). Esta passagem citada aqui não está incluída na ediçã̃o brasileira consultada para a redação do presente artigo.

${ }^{6}$ Sobre o conceito de disposição, cf. Harré (2001).
} 
posicionou claramente contra esse tipo de ideia defendida por Searle, segundo a qual fenômenos inconscientes existiriam apenas como algo codificado em estruturas físicas no cérebro. Nas palavras de Freud:

Neste ponto temos que estar preparados para ser confrontados com a objeção filosófica de que a representação latente não estaria disponível como objeto da psicologia, mas apenas como disposição física 【physische Disposition】 para a recriação do mesmo fenômeno psíquico, a saber, a mesmíssima representação. Mas poderíamos retrucar a isso que uma tal teoria uiltiapassa muito o domínio da psicologia propriamente dita, que ela simplesmente contorna o problema, ao insistir que 'consciente' e 'psíquico' são conceitos idênticos, e que essa teoria está claramente errada ao questionar o direito da psicologia de elucidar através de seus próprios meios uim de seus fatos mais típicos, como a memória. (Freud, 1982, p. 29).

Isso é o suficiente para mostrar que a concepção disposicional já era conhecida, e rejeitada, pelo criador da psicanálise, muito antes de sua articulação no pensamento de Searle. A partir de uma concepção como essa, segundo a qual um estado "mental" inconsciente não existe efetivamente como um fenômeno mental, mas apenas como uma disposição (uma propensão) para o surgimento de um estado consciente (que somente quando for consciente será, plenamente, um estado mental), Searle critica a noção comum de inconsciente como ingênua. Para ele, a visão comum dos estados mentais inconscientes é a de "um estado mental consciente menos a consciência" (Searle, 1992, p. 152 [218]), ou seja, o estado que não é consciente em um dado momento, mas que é exatamente igual a um estado consciente. Nessa visão ingênua, estados mentais inconscientes, são "como peixes mergulhados no mar. Os peixes que não podemos ver abaixo da superfície tem exatamente o mesmo aspecto que tem quando emergem" (Ibid., p. 152 [219]), ou, numa outra metáfora, "são como objetos armazenados no sótão escuro da mente. Estes objetos conservam suas formas o tempo todo, mesmo quando você não pode vê-los." (Ibid., p. 152 [219]).

Porém, é necessário questionar se essa concepção, de que fenômenos inconscientes preservam suas características básicas independentemente da consciência é algo assim tão risível, bem como questionar se a teoria disposicional de Searle, de fato, é coerente e sustentável. A tese do presente trabalho é que essa teoria enfrenta sérias dificuldades, pelo fato de Searle atribuir eficácia causal aos fenômenos inconscientes atribuição essa que, inclusive, é extremamente razoável, diante dos indícios trazidos, por exemplo, pela psicanálise e pelas ciências cognitivas ao longo das últimas décadas. 0 problema é que, ao aceitar essa eficácia (aparentemente pretendendo se conciliar com essas tradições intelectuais), ele está sendo incoerente com sua visão cartesiana da consciência como a essência do mental.

Após expor a visão de Searle sobre a consciência (seção 2), bem como sua teoria sobre os fenômenos inconscientes (seção 3), veremos (seção 4) como, ao atribuir eficácia causal tanto a sensações - caracterizadas por (a) aspecto qualitativo - quanto a estados intencionais, como desejos e intenções - caracterizados por (b) conteúdo representativo - Searle está se comprometendo (sem pretender) com a existência efetiva dessas propriedades mentais - (a) e (b) - nos momentos em que há causação. Mas, se é assim, então ele está comprometido com uma existência mental independente da consciência o que rompe com a visão cartesiana que ele pretende sustentar.

\section{A concepção de consciência de Searle}

Antes de mais nada, Searle anuncia sua adesão à ideia de que a consciência não pode ser, propriamente falando, definida (cf. Searle, 1992, p. 83 [123]; 2002, p. 21 [26]). Ela não pode ser definida de modo analítico, porque ainda não temos como exprimir a essência desse conceito, de modo que ele se restringe a oferecer o que ele chama de 
"definição de senso comum" (cf. Searle, 2002, p. 21 [26]), ou seja, meras indicações, através de exemplos, a respeito do fenômeno ao qual ele está se referindo (fenômeno que deve ser, então, objeto de investigação científica). Em certas passagens (cf., p. ex., Searle, 1992, p. 83 [124]), ele ilustra o que ele entende por consciência através do contraste entre a situação de alguém estar desperto, por um lado, e a situação de este alguém estar desacordado, por outro lado, o que mostra que a noção de Searle sobre a consciência envolve aquilo que Rosenthal (1997, p. 729) chama de consciência de criatura Na verdade, as caracterizações que Searle nos oferece a respeito da consciência parecem, claramente, transitar de modo indiscriminado entre dois conceitos delineados por Rosenthal (consciência de criatura e consciência de estado). ${ }^{7}$ Em A redescoberta da mente, Searle escreve:

O que entendo por "consciência" pode ser melhor ilustrado por exemplos. Se eu acordo de um sono sem sonhos, eu entro em um estado de consciência, um estado que prossegue enquanto eu estiver desperto. Se eu adormeço, sou colocado em anestesia geral, ou morro, meus estados de consciência cessam. (1992, p. 83 [124])

Nesta passagem, a consciência (inicialmente designada como um estado, no singular) é, explicitamente, apresentada como uma característica de um indivíduo, ou de um organismo (humano). Já em escritos um pouco posteriores, Searle oferece caracterizações como as seguintes:

Por "consciência" eu entendo simplesmente aqueles estados subjetivos de sensibilidade [sentience] ou ciência [awareness] que começam quando alguém acorda pela manhã de um sono sem sonhos e continuam através do dia até que esse alguém adormeça à noite, entre em coma, morra ou se torne de outro modo, como diria alguém "inconsciente". (Searle, 2002, p. 7 [1-2]). ${ }^{8}$

[A palavra] "consciência" se refere a aqueles estados de sensibilidade ou ciência que tipicamente começam quando nós despertamos de um sono sem sonhos e continuam durante o dia até que nós adormecemos novamente, entramos em coma, ou nos tornamos de outro modo "inconscientes". (Searle, 2002, p. 21 [26]). ${ }^{9}$

Nessas passagens, apesar da alusão a um estado de um organismo (que pode estar, em algumas situações, desperto ou, em outras situações, inconsciente), predomina a referência a estados (no plural), indicando uma multiplicidade de fenômenos mentais (como sensações, percepções, crenças e desejos) que ocorrem conscientemente quando o organismo está desperto.

Vemos, portanto, que se trata aqui de um conceito de consciência que congrega a condição de uma criatura que exemplifica fenômenos mentais com a condição desses mesmos fenômenos, vivenciados pela criatura consciente. Isso significa que o conceito proposto por Searle possui um caráter, em certo sentido, holístico, pois a consciência é

\footnotetext{
7 "Dois assuntos são frequentemente confundidos nas discussões sobre a consciência. uma questão é: o que é para um estado mental ser consciente. Supondo que nem todos os estados mentais são conscientes, nós queremos saber como os estados conscientes se diferenciam daqueles que não são. E ainda que todos os estados mentais fossem conscientes, nós ainda perguntaríamos em que consiste a sua consciência. Denominamos essa a questão da consciência de estado. Esse será meu principal tema no texto que segue. Mas nós não descrevemos apenas estados mentais como sendo conscientes ou não; nós também atribuímos consciência a criaturas. Assim, existe uma segunda questão, a questão sobre o que é para uma pessoa ou outra criatura ser consciente, ou seja, como criaturas conscientes se diferenciam daquelas que não são conscientes. Denominamos esta a questão da consciência de criatura." (Rosenthal, 1997, p. 729).

${ }^{8}$ Trata-se aqui de uma citação do texto "O problema da consciência", publicado originalmente em 1993.

${ }^{9}$ Trata-se aqui de uma citação do texto "Como estudar a consciência cientificamente", publicado pela primeira vez em 1998.
} 
concebida como uma totalidade, que articula diferentes aspectos. ${ }^{10}$ Entre as diversas características que ele identifica no fenômeno da consciência, Searle destaca, além do aspecto qualitativo e da subjetividade, a característica da unidade, segundo a qual diversos fenômenos mentais vivenciados a cada instante (por um sujeito consciente) se unificam em um único "campo" de consciência.

Os estados de consciência são qualitativos porque há sempre um modo como eles são sentidos por nós, um aspecto qualitativo característico que marca a maneira como os vivenciamos; e é interessante notar que esse aspecto qualitativo dos estados de consciência já implica a sua subjetividade, pois a qualidade implica que há um eu que a sente (cf. Searle, 2002a, p. 39-40 [57-58]; 2004, p. 134-35). E por ser qualitativa e subjetiva, a consciência tem de ser unificada (cf. Searle, 2004, p. 137). Os fenômenos mentais se integram à consciência e formam uma unidade, uma vez que "em formas não patológicas de consciência, nunca temos apenas, por exemplo, uma dor no cotovelo, uma sensação de calor ou a experiência de ver algo vermelho. Ao contrário, tudo isso ocorre simultaneamente em uma experiência consciente unificada" (Searle, 2002, p. 11-12 [9]). ${ }^{11}$

No tocante à característica da unidade, Searle distingue entre o que podemos chamar de seu aspecto sincrônico e seu aspecto diacrônico (cf. Costa, 2002, p. 206). Uma coisa é a unidade entre os diversos fenômenos mentais que vivencio em um dado instante (neste momento, vivencio a sensação das teclas na ponta de meus dedos, a sensação do surgimento das letras na tela do computador, a sensação do peso de meu corpo sobre o estofamento da cadeira, tudo isso, e muito mais, unido simultaneamente em una mesma experiência); outra coisa é a unidade de meus fenômenos mentais ao longo do tempo.

Na visão de Searle, um fenômeno mental é consciente na medida em que ele se integra a esse campo unificado de consciência, sendo que ele se inclina para o ponto de vista segundo o qual um fenômeno mental particular (como uma sensação específica, ou uma determinada crença) não é uma parte do campo de consciência, nem é algo que está em seu interior, mas sim uma modificação do campo pré-existente (embora ele admita que isso é uma hipótese, que precisa ser confirmada ou refutada por estudos empíricos cf. Searle, Searle, 2002, p. 54 [82], p. 55 [84]). De acordo com ele:

De fato, talvez seja um equívoco pensar a consciência como composta de partes. Afirmo que se pensarmos a consciência holisticamente, os aspectos que mencionei até aqui, em especial nossa combinação original de subjetividade, qualidade e unidade numa só característica, parecerão menos misteriosos. Emm vez de pensar meu estado atual de consciência como constituído de várias partes - a percepção da tela do computador, o som do riacho lá fora, as sombras projetadas na parede pelo sol do fim da tarde - devemos pensar tudo isso como modificações e formas que o campo consciente basal subjacente assume depois de meus terminais nervosos periféricos serem acionados pelos vários estímulos externos. (Searle, 2002, p. 56 [86]).

Essa passagem ajuda a compreender em que sentidos, na visão de Searle, estamos diante de um estado de consciência: não apenas no sentido de que é um estado em que um organismo (ou um cérebro) se encontra, mas também no sentido de que é um estado global que subjaz a todas as modificações que conhecemos como sendo fenômenos mentais particulares (como sensações e percepções específicas, como determinados pensamentos ou determinados sentimentos). Cada um deles seria a forma que o campo unificado assume sob determinadas circunstâncias.

\footnotetext{
${ }^{10}$ Ned Block (1997, p. 380) manifesta um posicionamento crítico em relação a esse modo como Searle concebe a consciência, ao afirmar que o tipo de caracterização feita por ele é falha, "porque ela indica coisas demais, muitas consciências diferentes".

${ }^{11}$ Cf. também Searle, 2004, p. 136; Searle, 2002, p. 41 [59-60]. No caso desta última referência, feita nesta nota, trata-se do texto "A consciência" publicado originalmente em 2000.
} 
Diante dessa concepção da consciência como um fenômeno holístico, coloca-se a pergunta a respeito dos fenômenos mentais inconscientes. Se o fenômeno mental consciente é aquele que se integra ao estado global descrito acima, qual é o modo de existência de um estado mental inconsciente na perspectiva de Searle? E é importante ressaltar que essa visão holística da consciência - na qual ela é um todo, do qual os estados, eventos e processos mentais são modificações - não abre nenhum espaço para uma existência propriamente mental fora do campo unificado (o que é uim sério problema, diante da eficácia causal que Searle atribui aos fenômenos mentais inconscientes). Como um fenômeno mental inconsciente poderia existir, se ele não é uma modificação do campo de consciência?

\section{A perspectiva de Searle sobre os fenômenos mentais inconscientes}

Como já foi exposto acima, Searle vê a consciência como o fenômeno mental mais importante, pois todos os outros fenômenos de nossa vida psicológica só podem ser considerados como, propriamente, mentais por meio de suas relações com a consciência (cf. Searle, 1992, p. 84 [125-26]). Em virtude dessa concepção, ele acredita que a ideia de ưm fenômeno mental inconsciente împlica a sua acessibilidade à consciência (cf. Searle, 1992, p. 156 [224]). Mesmo admitindo que muitos estados mentais jamais chegam a se tornar conscientes, e que muitos deles não podem se tornar conscientes por diversas razões (p. ex. por estarem fortemente recalcados), Searle defende que nossa noção de um estado mental inconsciente é, de certo modo, parasitária de nossa noção de um estado consciente (cf. Searle, 1992, p. 153-54 [221]) e para mostrar isso ele contrasta estados mentais inconscientes, como a nossa crença de que a Torre Eiffel está em Paris (quando não pensamos sobre esse fato) com estados do cérebro que podem até ter um papel na produção de estados mentais conscientes, como a mielinização dos axônios no sistema nervoso central, mas que jamais chamaríamos de estados "mentais".

A diferença entre eles é que o estado puramente neurológico, objetivo (descritível em termos oriundos do vocabulário da física, da química e da biologia) não é o tipo de coisa que poderia se tornar consciente (cf. Searle, 1992, p. 154 [222]), ao passo que uma crença, como a crença sobre a Torre Eiffel mencionada acima, é um estado mental genuíno, e é, assim, o tipo de coisa que, embora possa estar, na maior parte do tempo, inconsciente, tem a possibilidade de se tornar consciente.

De acordo com Searle, existem duas características da intencionalidade que uma teoria do inconsciente tem de ser capaz de explicar: (1) a distinção entre formas intrínsecas de intencionalidade e formas "como se", ou seja, a diferença entre um estado mental efetivamente intencional e uma atribuição metafórica de intencionalídade a algo que, na verdade, não é realmente intencional (cf. Searle, 1992, p. 78 [116-17]); e (2) o fato de que estados intencionais representam as suas condições de satisfação (aquilo que tem de ser o caso no mundo para que o estado intencional seja satisfeito - para que uma crença seja verdadeira, ou para que um desejo seja cumprido) apenas sob certos aspectos, e não outros, sendo que estes aspectos da representação tem de ser relevantes para o sujeito que exemplifica esses estados intencionais (cf. Searle, 1992, p. 155 [223]).

Essa forma aspectual dos estados intencionais intrínsecos pode ser ilustrada com fatos como o de que alguém pode acreditar que a estrela no céu é a estrela da manhã, sem acreditar que ela é a estrela da tarde, ou pode desejar um copo com água sem desejar um copo repleto de moléculas de $\mathrm{H}_{2} \mathrm{O}$ (cf. Searle, 1992, p. 157 [225-26]). Desejar o líquido tal como descrito em suas características superficiais é deseja-lo por um aspecto diferente do aspecto de sua composição química.

E essas duas características (expressas nos itens 1 e 2 acima) tem importantes consequências para a teorização sobre o inconsciente, pois elas são a base de uma argumentação para a tese de que todos os estados intencionais inconscientes são, em princípio, acessíveis à consciência, tese denominada por Searle de princípio da conexão entre consciência e intencionalidade. 
A argumentação de Searle para esse princípio pode ser resumida da seguinte maneira: certos estados são realmente intencionais (e não atribuições metafóricas) e apenas eles são genuinamente mentais. Estados intencionais inconscientes tem de ser intrínsecos ${ }^{12}$, e estados intencionais intrínsecos possuem formas aspectuais que (e esse é um passo decisivo na argumentação Searle) não podem ser caracterizadas exaustivamente em termos objetivos (como termos comportamentais ou os termos empregados na neurociência). Mas a ontologia de um estado intencional intrínseco, quando ele está inconsciente, consiste inteiramente em fenômenos objetivos. Isso parece sugerir que estados intencionais inconscientes não podem possuir formas aspectuais, já que não há nenhuma forma aspectual em fenômenos objetivos (cf. Searle, 1992, p. 159 [229], p. 161 [232]), mas Searle pretende escapar a esse problema através da ideia de que um estado intencional inconsciente pode preservar a sua forma aspectual (enquanto está inconsciente) no sentido de ele ser um possível conteúdo da consciência (cf. Searle, 1992, p. 159 [229]).

Mas qual o sentido de "possível" nesse contexto? Searle reconlhece que pode não ser efetivamente possível trazer um determinado estado intencional à consciência, em virtude de diversos fatores (repressão psicológica, lesões cerebrais, etc.), então, em qual sentido um estado intencional inconsciente (existindo na forma de um padrão de atividade eletroquímica no sistema cerebral) tem que poder se tornar consciente? A resposta de Searle está nas capacidades causais daqueles padrões de atividade eletroquímica (única existência real do estado intencional enquanto ele não está consciente), pois tais padrões de atividade, em sua existência puramente objetiva, possuem o poder de causar um estado intencional consciente, com sua forma aspectual e seu caráter vivencial (subjetivo), ainda que esses poderes possam ser bloqueados por outros poderes causais (como os de uma lesão cerebral que interfira no funcionamento do sistema, ou os poderes causais de outros padrões de atividade eletroquímica que realizem a repressão psicológica de um estado intencional).

Em outras palavras, pode ser concretamente impossível (em virtude da interferência de certas circunstâncias particulares) que um dado estado intencional se torne consciente, mas se ele é, de fato, um estado intencional real, ele tem de ser o tipo de coisa que, em princípio, poderia se tornar consciente. Nesse sentido, como já foi exposto na introdução do presente trabalho, Searle tem a clareza de que está propondo uma visão disposicional dos fenômenos mentais inconscientes, segundo a qual estes fenômenos não possuem uma existência mental efetiva (durante o tempo em que permanecem inconscientes), mas apenas uma existência enquanto a disposição que certos padrões de atividade neuronal possuem de causar estados mentais, nas circunstâncias adequadas.

Na perspectiva apresentada por ele, a característica de "ser parte" de um campo unificado de consciência, ou melhor, a característica de ser uma modificação de um campo unificado de consciência pré-existente, é uma característica intrínseca de quaisquer fenômenos mentais (efetivamente existentes), e a característica de poder ser uma modificação de um campo de consciência é uma característica necessária de quaisquer fenômenos mentais inconscientes (em sua condição disposicional).

Todavia, como já colocado na introdução do presente artigo, reconhecendo a importância dos fenômenos inconscientes para a explicação do comportamento humano (cf. Searle, 1992 p. 151 [217]; Searle, 2004, p. 250), Searle pretende conceder que esses fenômenos possuem eficácia causal sobre nossas ações. Mas, ao fazer isso, ele, inadvertidamente, rompe com os princípios de sua visão cartesiana da consciência, como veremos a seguir.

\footnotetext{
${ }^{12}$ Em seu conhecido texto "What is Consciousness?" David Armstrong (1997, p. 721) menciona o exemplo de um hipotético historiador do período medieval, sobre o qual ele afirma: "Não vamos negar que ele possui um grande número de conhecimentos e crenças sobre a idade média apenas porque ele está completamente adormecido." E sobre esse tipo de caso, Searle afirma com clareza: "pode ser dito corretamente a meu respeito que, mesmo quando estou completamente adormecido, eu acredito que George Washington foi o primeiro presidente dos Estados Unidos" (Searle, 2004, p. 239), indicando que essa crença é intrínseca.
} 


\section{O problema da eficácia causal do inconsciente}

Ao mesmo tempo em que concebe os fenômenos inconscientes como simples disposições que, portanto, gozam de uma existência mental meramente derivada, Searle aceita que tais fenômenos exercem eficácia causal. De fato, os indícios a favor dessa aceitação são significativos, e ele menciona um tipo de situação com a qual possivelmente muitos leitores estão familiarizados. Existem circunstâncias nas quais dores crônicas fazem com que uma pessoa doente acorde durante a noite (cf. Searle, 1992, p. 164 [236]), ou circunstâncias na quais um ferimento leva a pessoa adormecida a proteger o membro ferido, mesmo ela estando desacordada (cf. Searle, 2004, p. 244). Searle entende tais situações como indícios de que a dor continua a existir, de certa forma, pois ela é capaz de exercer efeitos causais sobre o funcionamento ou a movimentação do corpo. De acordo com ele:

O que nos predispõe a dizer que a dor continuou a existir, ainda que inconsciente, é que havia um processo neurofisiológico subjacente capaz de gerar um estado consciente e capaz de gerar comportamento apropriado a alguém que tivesse esse estado consciente. (Searle, 1992, p. 165 [237], grifo meu).

Isso significa que, esse processo inconsciente, o qual - caso o sujeito estivesse desperto - seria capaz de causar uma modificação no campo unificado de consciência que ele vivencia, continua capaz de causar determinado tipo de comportamento, mesmo quando não há consciência. E ele se baseia nesse tịpo de situação relativo a dores para elucidar a situação daquilo que Freud denominou "inconsciente dinâmico", ou seja, "estados mentais que funcionam causalmente no comportamento [de um agente], onde ele está totalmente inconsciente [unaware] do funcionamento desses estados mentais e pode até mesmo nega-los sinceramente." (Searle, 2004, p. 240). Neste caso, estamos lidando com fenômenos intencionais, que, portanto, tem como uma característica essencial uma certa forma aspectual. E o exemplo das dores nos ajudaria a entender a eficácia causal do inconsciente dinâmico. Nas palavras de Searle:

Note que nesse caso a neurobiologia é capaz de causar a dor em uma forma consciente, mesmo quando estou dormindo e não sinto dor alguma. Porém, e esse é o ponto crucial para esta parte da discussão, a neurobiologia que é capaz de causar a dor em uma forma consciente também é capaz de causar o comportamento apropriado para evitar a dor mesmo quando eu não sinto a dor. Agora o mesmo parece exatamente correto para descrever os casos de inconsciente dinâmico reprimido. $O$ agente não está consciente de qualquer motivação quando o inconsciente dinâmico está ativo. No entanto há uma estrutura neurobiológica que é capaz tanto de causar a motivação como parte de seus pensamentos conscientes quanto de causar o comportamento apropriado a quem tem a motivação. (Searle, 2004, p. 244-45).

Mas se a dor inconsciente está causando o mesmo comportamento que causaria se estivesse consciente, ela só pode fazer isso em virtude de sua característica definidora, seu (a) aspecto qualitativo, que é uma propriedade genuinamente mental. Da mesma forma, se o desejo ou a intenção inconsciente está causando uma determinada ação, mesmo que o sujeito não se dê conta disso, esses estados intencionais tem que fazer isso em virtude de seu (b) conteúdo representativo, com sua específica forma aspectual - que, para Searle é a característica essencial dos estados intencionais (cf. Searle, 2004, p. 247).

Se Searle negasse que essas características - (a) e (b) - são essenciais para a causação, ele estaria recaindo em um epifenomenalismo, a visão de que fenômenos mentais são epifenômenos de processos físicos e, portanto, não possuem eficácia causal - uma visão que Searle vem rejeitando enfaticamente ao longo de toda a sua carreira (cf. Searle, 1980, p. 455; Searle, 1983, p. 263-64 [365-66]; Searle, 2004, p. 114; Searle, 2007, p. 
171) - pois ele estaria admitindo circunstâncias nas quais processos cerebrais seriam as únicas causas de ações nossas (ações que normalmente atribuímos a fenômenos mentais).

Concentremo-nos no caso dos estados intencionais inconscientes (inconsciente dinâmico), pois eles estão diretamente envolvidos no núcleo da teoria de Searle: a ideia de uma conexão entre a consciência e o inconsciente (cf. Searle, 2004, p. 246). ${ }^{13}$ Se um desejo inconsciente, ou ulma intenção inconsciente, é capaz de causar alguma ação, ela só pode fazer isso em virtude de sua específica forma aspectual, do contrário, o conteúdo do estado intencional seria de tal modo indeterminado que ele não poderia ser relacionado precisamente ao efeito. Se Jimmy vai ao shopping, em determinado dia e horário, com a intenção de comprar certo produto, mas inconscientemente vai em virtude do desejo de encontrar Sally - que trabalha no shopping, e fica livre naquele horário - esse desejo só pode ser a causa inconsciente da ação de ir ao shopping em virtude de sua específica forma aspectual, pois um desejo sem forma aspectual é incapaz de delimitar exatamente suas condições de satisfação (aquilo que tem que ser o caso para que o desejo seja satisfeito), de modo que esse desejo teria dificuldades em especificar uma ação capaz de satisfaze-lo.

O problema é que Searle afirma, reiteradamente, que a forma aspectual não existe no nível neurobiológico, de modo que um estado meramente disposicional não poderia ter uma forma aspectual efetiva, ocorrente. De acordo com ele:

A ontologia da intencionalidade inconsciente consiste inteiramente em fenômenos neurofisiológicos, objetivos, de terceira pessoa, mas ainda assim os estados têm uma forma aspectual que não pode ser constituída por tais fatos, porque não há nenhuma forma aspectual no nível de neurônios e sinapses. (Searle, 1992, p. 159 [229], grifo meu. Cf. também Ibid., p. 161 [232])

Mas se "a neurobiologia como tal não tem forma aspectual" (Searle, 2004, p. 247), e se o estado inconsciente existe - na forma de uma disposição - enquanto um processo neurobiológico, então ele não poderia ter forma aspectual. A solução de Searle é que essa forma (justamente) existe de maneira disposicional. Mas o meu ponto é que, se a forma aspectual desempenha um papel na causação de ações, então ela, simplemente, não pode existir como simples disposição. Ela tem que existir efetivamente, ou seja, de modo ocorrente.

Vejamos a maneira como Searle argumenta a favor de sua teoria disposicional. Exponlho abaixo uma argumentação resumida, baseada nas elaborações do próprio Searle (cf. Searle, 1992, p. 156-61 [224-31]; Searle, 2004, p. 246-47):

(1) Estados intencionais inconscientes são intrínsecos

(2) Estados intencionais intrínsecos sempre tem formas aspectuais

(3) Estados intencionais inconscientes existem na forma de fenômenos neurobiológicos

(4) Fenômenos neurobiológicos não possuem forma aspectual ocorrente

(5) Estados intencionais inconscientes têm que ser estados conscientes possíveis

Logo: (6) A ontologia do inconsciente consiste em características objetivas do cérebro capazes de causar pensamentos conscientes

Nessa teoria, a visão disposicional - expressa na tese (6) - seria responsável por conciliar a necessidade de uma forma aspectual - tese (2) - com a inexistência de formas aspectuais no nível neurobiológico - tese (4). A forma aspectual do estado não existiria efetivamente, existiria apenas de modo potencial, mas seria produzida em forma efetiva desde que surgissem as circunstâncias adequadas. O problema para essa teoria se torna

${ }^{13}$ Ou seja, o argumento de Searle para a conexão entre o inconsciente e a consciência é baseado na forma aspectual, que é uma característica essencial de estados intencionais - tanto conscientes quanto inconscientes. 
claro quando consideramos que, para causar uma ação, um estado mental tem que ter uma forma aspectual, de modo que os estados intencionais inconscientes precisam, sim, ter uma forma aspectual ocorrente. Se formularmos as teses com as quais Searle está comprometido - em virtude de sua aceitação da eficácia causal dos estados inconscientes - perceberemos que essas teses o comprometem com conclusões incompatíveis com a teoria disposcional resumida acima. Se observarmos a argumentação de Searle reconstituída acima, não será difícil perceber que, das premissas (1) e (2):

(1) Estados intencionais inconscientes são intrínsecos

(2) Estados intencionais intrínsecos sempre tem formas aspectuais

\section{Segue-se: (2') Estados intencionais inconscientes sempre têm formas aspectuais}

Levando em consideração a premissa (3), de que estados inconscientes existem como processos cerebrais, acrescentemos a tese (4'), aceita por Searle, de que estados intencionais inconscientes exercem eficácia causal sobre nossas ações, e acrescentemos também a tese $\left(5^{\prime}\right)$, fundamentada acima, de que essa eficácia causal tem que decorrer da forma aspectual do estado intencional inconsciente:

(3) Estados intencionais inconscientes existem na forma de fenômenos neurobiológicos

(4) Estados intencionais inconscientes causam ações humanas

(5) Estados intencionais (conscientes ou inconscientes) exercem eficácia causal em virtude de sua forma aspectual

E esta última premissa implica que, no momento em que a eficácia causal é exercida, a sua forma aspectual tem que ocorrer efetivamente, e não existir de forma meramente disposicional. Formulemos, então, essa premissa (6”):

(6) Se estados intencionais inconscientes exercem eficácia causal no tempo t, então a sua forma aspectual tem que existir de modo ocorrente em $t$

Um primeiro problema para a argumentação de Searle exposta acima é que das premissas $\left(2^{\prime}\right),(3),\left(4^{\prime}\right),\left(5^{\prime}\right)$ e $\left(6^{\prime}\right)$, segue-se uma conclusão que contradiz uma das premissas do argumento anteriormente exposto, a saber:

\section{(7) Fenômenos neurobiológicos possuem forma aspectual ocorrente}

Pois se estados intencionais inconscientes sempre tem formas aspectuais (tese $2^{2}$ ), existem na forma de fenômenos neurobiológicos (tese 3 ), causam ações humanas (tese $4^{\prime}$ ) em virtude de sua forma aspectual (tese $5^{\prime}$ ), de modo que, no momento em que a ação é causada, a forma aspectual tem que existir de modo ocorrente (tese $6^{7}$ ), é claro que um determinado tipo de fenômenos neurobiológicos - justamente os fenômenos neurobiológicos que são estados intencionais inconscientes - precisam ter uma forma aspectual atualizada, e não apenas de maneira potencial (tese 7).

Mas se essa é uma questão importante para que se possa avaliar a teoria disposicional do inconsciente, gostaria de deixa-la de 1 ado $^{14}$, e destacar um outro aspecto que me parece ainda mais importante. O problema explicitado acima é o de que Searle está comprometido com uma conclusão (tese 7), que contradiz uma das premissas de seu argumento (tese 4). Mas essa não é a única incoerência em que ele incorre em sua teorização sobre o inconsciente, pois a eficácia causal dos fenômenos inconscientes o

${ }^{14}$ Para uma discussão dessa questão, mas a partir de um ponto de vista diferente do adotado aqui, cf. Prata (2017). 
compromete, também, com uma tese incompatível com o caráter fundamental que ele atribui à consciência no domínio do psíquico.

De algumas das premissas enunciadas acima, referentes ao tema da causação inconsciente de ações, é possível deduzir, em determinadas circunstâncias - ou seja: quando causam uma ação - que estados intencionais inconscientes possuem propriedades mentais ocorrentes, de modo que, em tais circunstâncias, propriedades mentais existem sem a presença de consciência:

(2') Estados intencionais inconscientes sempre têm formas aspectuais

(4') Estados intencionais inconscientes causam ações humanas

(5") Estados intencionais inconscientes causam ações em virtude de sua forma aspectual $1^{15}$

(6) Se estados intencionais inconscientes exercem eficácia causal no tempo t, então a sua forma aspectual tem que existir de modo ocorrente no tempo $t$

(8) Se estados intencionais inconscientes possuem forma aspectual ocorrente no tempo $t$, então eles possuem uma propriedade mental independentemente da consciência em $t$

Sendo intrínseco, um estado intencional inconsciente sempre tem forma aspectual (tese $2^{\prime}$ ), e se ele causa uma ação (tese $4^{\prime}$ ), ele o faz em virtude dessa forma (tese $5^{\prime \prime}$ ), de modo que no instante em que ele causa essa ação, a forma aspectual tem que ser ocorrente (tese $6^{\prime}$ ). Portanto, no instante em que um estado intencional inconsciente causa uma ação, ele instancia uma propriedade mental que está ocorrendo sem consciência (tese 8). Pode ser que estados intencionais inconscientes tenham que ser estados conscientes possíveis (tese 5), no sentido de que todo estado inconsciente deva ter o potencial de se tornar consciente. Mas a argumentação que acabamos de expor mostra que a ontologia do inconsciente não pode ser semre a de características objetivas do cérelbro capazes de causar pensamentos conscientes (tese 6), pois em alguns casos, de acordo com Searle, há causação mental inconsciente, e se um estado intencional inconsciente causa algo, então sua forma aspectual tem que existir efetivamente, e não apenas de modo disposicional. Mas se o estado intencional tem uma forma aspectual atualizada, então ele tem uma ontologia - um modo de existência - propriamente psicológica.

Em suma: a discussão das teses relativas à causação mental inconsciente mostra que a ontologia do inconsciente - a maneira como estados inconscientes existem - além do potencial de causar estados de consciência, pode, em determinadas circunstâncias, incluir propriedade mentais genuínas, o que equivale a dizer que temos um estado propriamente mental, mas que existe independentemente do campo unificado de consciência.

\section{Considerações finais}

Entendo que a grande importância do tema da consciência para a compreensão teórica de nossa vida mental não é obstáculo para a aceitação de fenômenos mentais inconscientes, pois ao mesmo tempo em que a consciência é importante, ela pode ser concebida como um desenvolvimento sofisticado, que se baseia em fenômenos mais fundamentais (cf. Armstrong, 1997, p. 721). Searle acerta quando ele procura dar vum lugar de destaque para os fenômenos mentais inconscientes em nossa vida psíquica, pois os indícios nesse sentido são muito numerosos, e muito convincentes.

Entretanto, a eficácia causal que esses fenômenos, de fato, parecem possuir, é um obstáculo enorme para a teoria disposicional de Searle, pois ela abala a visão cartesiana da consciência como essência do mental, que é o motivo para se articular uma

${ }^{15}$ Esta tese é uma reformulação da tese (5’) exposta acima, reformulação restrita ao caso dos estados intencionais inconscientes. 
teoria disposicional do inconsciente em primeiro lugar. Se um fenômeno inconsciente está, num tempo t, exercendo eficácia causal, esse fenômeno tem que possuir, no tempo t, uma forma aspectual ocorrente, do contrário esse fenômeno mental não conseguiria determinar precisamente suas condições de satisfação (que são decisivas para aquilo que será causado pelo fenômeno inconsciente). Mas se tal fenômeno possui uma forma aspectual ocorrente, então ele instancia efetivamente uma propriedade genuinamente mental, de modo que, no exato instante em que causa uma ação, o estado intencional inconsciente possui uma existência propriamente mental. Mas se ele é inconsciente, isso significa que essa existência mental é independente da consciência.

No meu modo de entender, a visão que emerge desse fracasso da visão cartesiana (em explicar a causação mental inconsciente), é uma visão na qual fenômenos inconscientes até podem em muitas (talvez na maioria das) situações, existir de modo puramente disposicional. Certamente nos encontramos em incontáveis estados mentais que não existem de modo atual, de modo que é muito razoável concebe-los como disposições. Mas quando fenômenos inconscientes causam efeitos em nossas ações (e por meio delas no mundo extra-psíquico) eles estão gozando de uma existência atualizada que, provavelmente, é uma existência neurobiológica ${ }^{16}$, mas que é uma existência exterior ao campo de consciência. Desse modo tais fenômenos (neurobiológicos) possuem a capacidade (disposição) de causar estados conscientes, mas possuem essa capacidade como uma propriedade secundária, que ocorre contingentemente, dadas certas circunstâncias, e não como sua propriedade fundamental, definidora de seu modo de existência ${ }^{17}$, como defende Searle.

\section{Referências}

Adam, Ch. (Org.): Tannery, P. (Org.). Ouvres de Descartes - Meditationes de prima philosophia. Paris: Vrin, 1996. (Vol. VII).

Adam, Ch. (Org.); Tannery, $\mathbb{P}$. (Org.). Ouvres de Descartes - Méditations et príncipes (traduction française). Paris: Vrin, 1996. (Vol. IX).

Armstrong. A. "What is Consciousness?". In: Block, N. (Org.); Flanagan, O. (Org.); Guizeldere, G. (Org.). The Nature of Consciousness: Philosophical Debates. Cambridge (Massachusetts): MIT Press, pp. 721-728, 1997.

Armstrong, A. The Mind-Body Problem: An Opinionated Introduction. Boulder (CO); Oxford (UK): Westview Press, 1999.

Bieri, P. "Was macht Bewusstsein zu einem Råtsel?" In: Metzinger (Org.) Bewusstsein: Beiträge aus der Gegenwartsphilosophie. $3^{\mathrm{a}}$ ed. Paderborn, Munique, Viena, Zurique: Schöningh, 1996.

Block, N. "On a Confusion About a Function of Consciousness" In: Block, N. (Org.); Flanagan, O. (Org.); Güzeldere, G. (Org.). The Nature of Consciousness: Philosophical Debates. Cambridge (Massachusetts): MIT Press, pp. 375-415, 1997.

Brentano, F. Psychologie vom empirischen Standpunkt. 2a ed. Leipzig: Meiner, 1924.

Brentano, F. Psychology from an empirical standpoint. London: Routledge \& Kegan Paul, 1995.

${ }^{16}$ Assim como Searle (1992, p. 253 [364]), entendo que dizer que os fenômenos mentais possuem uma existência neurobiológica não implica que eles não sejam genuinamente mentais.

${ }^{17}$ Para Searle, um fenômeno inconsciente é mental somente na medida em que ele é capaz de causar um estado de consciência. 
Chalmers, $\mathbb{D}$. "Facing up to the Problem of Consciousness". Journal of Consciousness Studies. Vol. 2, nº 3, pp. 200-219, 1995.

Chalmers, $\mathbb{D}$. The Conscious Mind: In Search of a Fundamental Theory. Oxford: Oxford University Press, 1996.

Churchland, P. Matéria e Consciência: Uma introdução contemporânea à Filosofia da Mente. São Paulo, UNESP, 2004.

Costa, C. Uma introdução contemporânea À filosofia. São Paulo: Martins Fontes, 2002.

Descartes, R. Discurso do método; Meditações; Objeções e Respostas; As Paixões da Alma; Cartas. 2a Edição. São Paulo: Abril Cultural (Os Pensadores), 1979.

Freud, S. Vorlesungen zur Einführung in die Psychoanalyse. Neue Folge der Vorlesungen zur Einführung in die Psychoanalyse. Frankfurt am Main: Fischer Taschenbuch Verlag, 1982. (Studienausgabe Band I).

Gennaro, $\mathbb{R}$. Consciousness and Selfconsciousness: a Defense of the Higher Order Thought Theory of Consciousness. Amsterdam/Philadelphia: John Benjamins Publishing, 1996.

Güzeldere, G. "Introduction - Many Faces of Consciousness: A Field Guide". In: Block, N. (Org.); Flanagan, O. (Org.); Güzeldere, G. (Org.). The Nature of Consciousness: Philosophical Debates. Op. cito, pp. 1-67, 1997.

Harré, R. "Dispositions and Powers" In: W. H. Newton-Smith (ed.). A Companion to the Philosophy of Science. Oxford: Blackwell, pp. 97-101, 2001.

Jackson, F. "Epiphenomenal Qualia" In: Philosophical Quarterly, 32: 127-36, 1982.

Kripke, S. Naming and Necessity. Cambridge (Mass.): Harvard University Press, 2001. [Publicação original em 1972].

Levine, J. "Materialism and Qualia: The Explanatory Gap" In: Pacific Philosophical Quarterly 64, 354-61, 1983.

Loux, M. Metaphysics: a Contemporary Introduction. London: Routledge, 2006.

Maslin, K. T. Filosofia da mente. 2a edição, Porto Alegre: Artmed, 2009.

Nagel, T. "What Is It Like to Be a Bat?" In: Philosophical Review Vol. 83, pp. 435-50, 1974.

Prata, T. A. "A concepção disposicional do inconsciente na Filosofia da Mente de John Searle" In: Revista Reflexões, Ano 6, № 11, pp. 201-16, 2017.

Rosenthal, D. "Two Concepts of Consciousness". In: Philosophical Studies 49, pp. 329-59, 1986.

Rosenthal, D. "A Theory of Consciousness". In: Block, N. (Org.); Flanagan, O. (Org.); Guizeldere, G. (Org.). The Nature of Consciousness: Philosophical Debates. Op. cito, pp. 729-753, 1997.

Searle, J. R. "Intrinsic Intentionality" In: Behavioral and Brain Sciences 3, p. 450-456, 1980.

Searle, J. R. Intentionality: An Essay in the Philosophy of Mind. Cambridge: Cambridge University Press, 1983.

Searle, J. R. The Rediscovery of the Mind. Cambridge Mass., London: MIT Press, 1992.

Searle, J. R. Intencionalidade. São Paulo: Martins Fontes, 1995.

Searle, J. R. A Redescoberta da Mente. São Paulo: Martins Fontes, 1997.

Searle, J. R. Consciousness and Language. Cambridge (UK): Cambridge University Press, 2002. 
Searle, J. R. Mind: A Brief Introduction. Oxford: Oxford University Press, 2004.

Searle, J. R. "Dualism Revisited" In: Journal of Physiology - Paris 101, pp. 169-78, 2007.

Searle, J. R. Consciência e linguagem. São Paulo: Martins Fontes, 2010.

Doutor em Fillosofila (Ruprecht-Karl Universität Heidelberg, 2007)

Professor Adjunto, Departamento de Filosofia (UFPE)

E-mail: tarik.de athayde prata@aluminini-heidelberg, de 